\title{
Additional Resistance Gene(s) Against Cladosporium fulvum Present on the Cf-9 Introgression Segment Are Associated with Strong PR Protein Accumulation
}

\author{
Richard Laugé, ${ }^{1}$ Alexander P. Dmitriev, ${ }^{2}$ Matthieu H. A. J. Joosten, ${ }^{1}$ and Pierre J. G. M. De Wit ${ }^{1}$ \\ ${ }^{1}$ Department of Phytopathology, Wageningen Agricultural University, Binnenhaven 9, 6709 PD Wageningen, \\ The Netherlands; 'Laboratory of Molecular Plant Pathology, Institute of Cell Biology and Genetic \\ Engineering, 148 Zabolotnogo Str., $252143 \mathrm{Kiev}$, Ukraine \\ Accepted 2 January 1998.
}

\begin{abstract}
The existence of a gene or genes conferring weak resistance against the fungal tomato pathogen Cladosporium fulvum, in addition to the $C f-9$ resistance gene, present on the Lycopersicon pimpinellifolium $C f-9$ segment introgressed into $L$. esculentum, was demonstrated with strains of C. fulvum lacking a functional Avr9 avirulence gene and tomato genotypes lacking a functional $C f$-9 gene, respectively. Two mutant strains, obtained by disruption of Avr9 in race 4 and race 5 of $C$. fulvum, do not trigger the hypersensitive response-mediated resistance on MM-Cf9 genotypes that is normally induced after recognition of the AVR9 elicitor. However, when these strains are inoculated onto MM-Cf0 and MM-Cf9 genotypes, adult MM-Cf9 plants still show weak resistance. This resistance is not related to the $C f-9$ gene, as ethyl methanesulfonate (EMS)-generated $C f-9$ mutants retained weak resistance. Growth of the fungus in the leaf mesophyll is strongly inhibited, whereas re-emergence of fungal mycelium and conidiation are poor. Strong accumulation of pathogenesisrelated proteins and early leaf chlorosis are associated with this phenotype of weak resistance. A search among natural strains lacking the Avr9 gene revealed that one strain is able to overcome this weak resistance. Possible mechanisms underlying this weak resistance are discussed. The presence of the additional weak resistance gene(s) could explain why the resistance of $\mathrm{Cf} 9$ genotypes has not been overcome so far in practice.
\end{abstract}

The imperfect fungus Cladosporium fulvum Cooke causes leaf mold disease on tomato (Lycopersicon esculentum Mill.). Under high humidity conditions, conidia of the fungus present at the lower side of tomato leaves germinate, form runner hyphae, and grow over the surface until open stomata are encountered. After penetration through stomata, the fungus develops biotrophically in the apoplastic space of the mesophyll, without producing specialized feeding structures. After 2 to 3 weeks, the fungus emerges from the leaf tissue through stomata and conidiophores develop that produce large amounts of conidia (De Wit 1977).

Corresponding author: Pierre J. G. M. De Wit; Phone: +31-317-483130; Fax: +31-317-483412; E-mail: Pierre.DeWit@ Medew.FYTO.WAU.NL
Resistance toward C. fulvum has been found in several wild species of the genus Lycopersicon. Resistance is a monogenic dominant character and provides either an immune type of resistance, which is based on a hypersensitive response (HR) allowing no fungal colonization, as has been described for the $C f-2, C f-4, C f-5$, and $C f-9$ resistance genes, or a weak type of resistance in which residual colonization takes place, such as for the $C f-1$ and $C f-3$ resistance genes (Stevens and Rick 1988). Genetic variation of the fungus has resulted in the appearance of new physiologic races that could overcome resistance genes introgressed into commercial tomato cultivars (Day 1956, 1957). New resistance genes were found in wild Lycopersicon spp. (Kanwar et al. 1980; Stamova and Yordanov 1977, 1978a, 1978b). So far all resistance genes used in breeding programs act independently. Additional C. fulvum resistance genes have been described; however, allelism tests have not yet been conducted systematically to prove that these genes are distinct from already characterized resistance genes. Apparently, many independent resistance genes toward C. fulvum occur in nature.

Four resistance genes, $C f-2, C f-4, C f-5$, and $C f-9$, introgressed from three different Lycopersicon spp., have been investigated in detail. $C f-4$ and $C f-9$ are closely linked on chromosome 1, while $C f-2$ and $C f-5$ are closely linked on chromosome 6 (Jones et al. 1993). Furthermore, $C f$-1, a weak resistance gene, maps near the $C f-4 / C f-9$ genes (Langford 1937; Kerr and Bailey 1964). Thus, a number of the $C f$ genes appear to be clustered.

Molecular analysis of proteins secreted by C. fulvum during its growth in the apoplast of tomato leaves led to the identification of the race-specific elicitors AVR9 and AVR4 (Scholtens-Toma and De Wit 1988; Joosten et al. 1994). These proteinaceous elicitors govern recognition of the fungus by resistant plants carrying the resistance genes $C f-9$ and $C f-4$, respectively. The two encoding genes, $A v r 9$ and $A v r 4$, and the matching resistance genes $C f-9$ and $C f-4$, respectively, comply with the gene-for-gene hypothesis (Van den Ackerveken et al. 1992; Joosten et al. 1994).

Cloning of the four $C f$ genes revealed that they are highly homologous (Jones et al. 1994; Dixon et al. 1996; HammondKosack and Jones 1997). They encode putative extracellular glycoproteins containing leucine-rich repeats (LRRs), with a transmembrane domain and a short C-terminal cytoplasmic 
tail. They differ mainly in the number of LRRs and certain amino acids in the LRRs (Jones et al. 1996). Southern analyses of the tomato genome demonstrated that these genes constitute gene families (Jones et al. 1996) and sequence analyses showed that $C f$ genes are organized in clusters of homologues (Hammond-Kosack and Jones 1997). The $C f-9$ gene was shown to be part of a region containing five homologous genes, among which one is the functional $C f-9$ gene. This finding suggested that homologues of the $C f$ genes might have the capacity to recognize yet unidentified elicitors of C. fulvum.

To test whether $C f$ resistance genes, in addition to the functional $C f-9$ gene, are present on the $C f-9$ introgression frag- ment from L. pimpinellifolium we used two transgenic fungal strains in which the Avr9 gene has been disrupted (Marmeisse et al. 1993). In the absence of the AVR9 elicitor, presence of the functional $C f-9$ gene would no longer result in recognition of these strains, but $C f-9$ homologues of the cluster or other genes at the locus might still do so. Here we report on virulence of Avr9 mutants on near-isogenic lines of the tomato cv. Moneymaker, either lacking the $C f-9$ introgression segment (MM-Cf0), or containing the $C f-9$ introgression segment with (MM-Cf9) or without (MM-Cf9/Cf-9 mutant) a functional $C f$ 9 gene. Results indicate that additional $C f$ resistance gene(s) are present on the $C f-9$ introgression segment, whose function is $A v r 9 / C f$-9-independent.
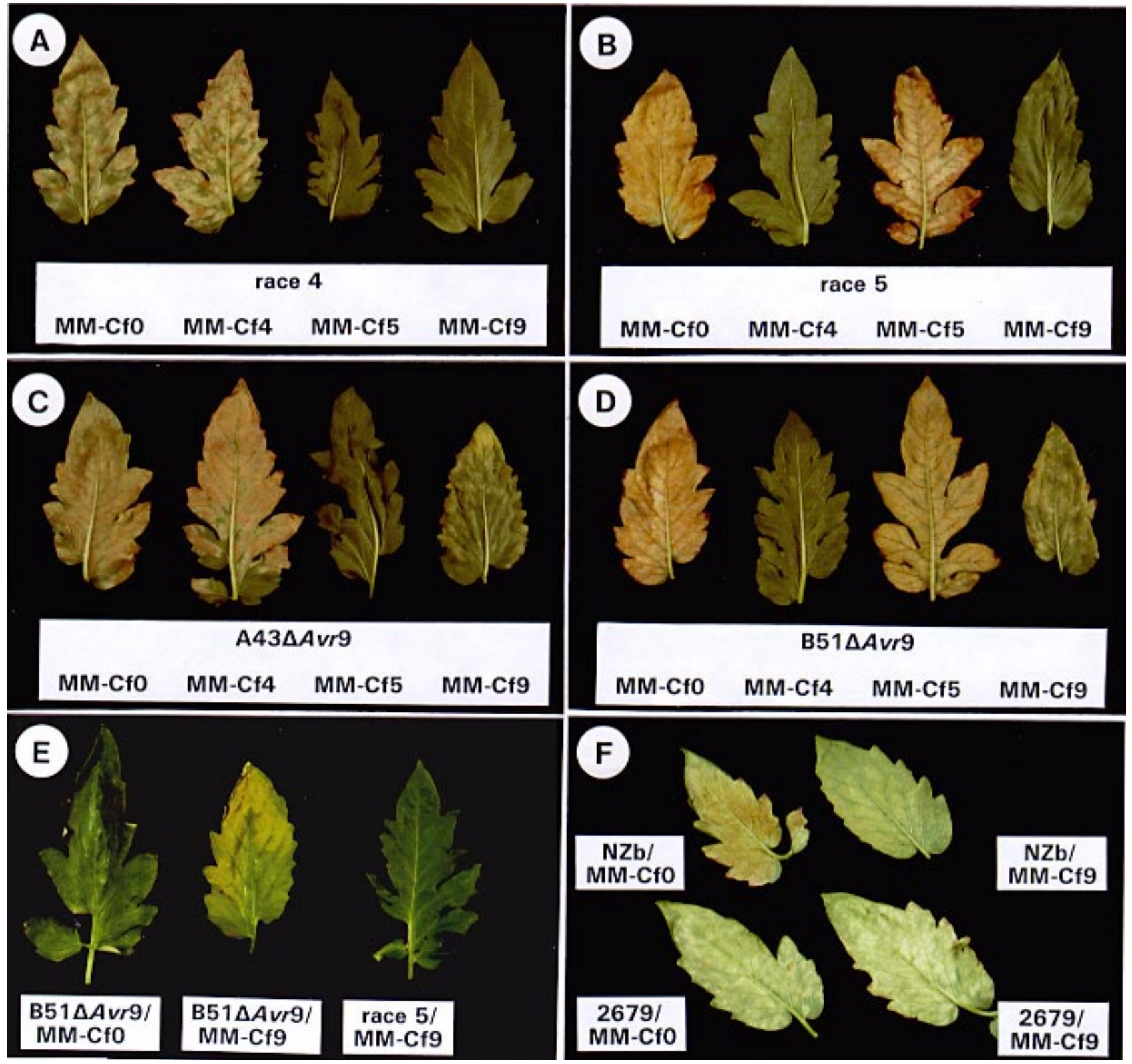

Fig. 1. Disease symptoms present at the lower side of leaflets of near-isogenic lines of the tomato cv. Moneymaker carrying different $C f$ resistance genes, 3 weeks post inoculation with (A) race 4, (B) race 5, (C) Avr9-disrupted strain A43 $\Delta A v r$, and (D) Avr9-disrupted strain B51 $\Delta A v r$. Emerging mycelium forms white and brown patches that will eventually release conidia. E, Disease symptoms present at the upper side of leaflets 2 weeks post inoculation; from left to right, MM-Cf0 plants inoculated with the strain B51 $\Delta A v r 9$, MM-Cf9 plants inoculated with B51 $\Delta A v r 9$, and MM-Cf9 plants inoculated with race 5. F, Symptoms at the lower side of leaflets of MM-Cf0 and MM-Cf9 plants 3 weeks post inoculation with the natural Avr 9 mutants NZb and 2679. 


\section{RESULTS}

\section{A weak resistance, present on the $C f-9$ introgression segment, is independent of AVR9 recognition.}

Fungal strains, race 4 , race 5 , and the two corresponding isogenic strains obtained after disruption of the Avr9 gene, $\mathrm{A} 43 \Delta A v r 9$, and $\mathrm{B} 51 \Delta A v r 9$, were inoculated on MM-Cf0, MM-Cf4, MM-Cf5, and MM-Cf9 tomato genotypes.

After colonization of the mesophyll, fungal mycelium emerges through stomata at the lower side of the leaf, and the density of the white and brown mycelium patches is a measure of disease severity. Symptoms developed 3 weeks post inoculation are presented in Figure 1A, B, C, and D. From Figure 1 it is clear that the tomato genotype without a known resistance gene (MM-Cf0) is fully susceptible to all races of C. fulvum, irrespective of whether the Avr9 gene is present or absent. Similarly, the MM-Cf4 and MM-Cf5 tomato genotypes are fully susceptible to race 4 and race 5, respectively, as well as to the corresponding isogenic Avr9-disrupted strains, A $43 \Delta A v r 9$ and B51 $\Delta A v r 9$, respectively. The severity of the disease symptoms caused by these strains on MM-Cf4 and MM-Cf5 is not different from the severity of the disease symptoms caused on MM-Cf0. However, the severity of the disease symptoms caused by strains $\mathrm{A} 43 \Delta A v r 9$ and $\mathrm{B} 51 \Delta A v r 9$ on MM-Cf0 and MM-Cf9 is different. Strains lacking the Avr 9 gene, generated in two independent fungal genetic backgrounds, cause less disease symptoms on MM-Cf9 than on MM-Cf0. These observations indicate that a second weak type of resistance, in addition to the Avr $9 / C f$-9-mediated HR-type of resistance, is present on the segment introgressed from $L$. pimpinellifolium into MM-Cf9 plants. This resistance is clearly different from the full resistance induced by the recognition of AVR 9 mediated by the $C f-9$ gene, as disease symptoms are still present. Differences in the severity of the disease symptoms were reproducible between the plant individuals within the same inoculation experiment and between repeated experiments. Interestingly, there is no difference in the severity of the disease symptoms between the MM-Cf0 and the MM-Cf4 genotypes upon inoculation with race 4, nor between the MM-Cf0 and the MM-Cf5 genotypes upon inoculation with race 5 . The latter observation suggests that, at least with the two fungal strains tested, no additional weak resistance is conferred by the MM-Cf4 and MM-Cf5 genotypes that contain introgression segments originating from L. hirsutum and L. esculentum var. cerasiforme, respectively.

\section{The weak resistance is independent of the presence of a functional $\boldsymbol{C} \boldsymbol{f}-\boldsymbol{9}$ gene.}

The weak resistance is independent of $A v r 9$, one partner of the $A v r 9 / C f-9$ gene pair. We checked whether it is also independent of the other partner, the $C f-9$ resistance gene. We used MM-Cf $9 / C f-9$ mutant genotypes that were obtained by ethyl methanesulfonate (EMS) treatment of MM-Cf9 plants (Hammond-Kosack et al. 1994). The resulting plants carry the L. pimpinellifolium introgression segment lacking a functional $C f-9$ gene.

Upon inoculation with the two Avr9 mutants, the $C f-9 \mathrm{mu}-$ tants show disease symptoms that are similar to those observed on MM-Cf9 plants, indicating that the weak resistance factor is present in the $C f-9$ mutants (data not shown). Therefore, this weak resistance is independent of the $C f-9$ resistance gene and does not relate to some secondary function of $C f-9$. As expected, it was observed that the $C f-9$ mutants, which are no longer responsive to AVR9, exhibit weak resistance toward the wild-type strains, races 4 and 5 .

\section{The weak resistance results in inhibition of fungal growth and conidiation.}

Fungal growth inside the leaf was studied by light microscopy 20 days post inoculation (Fig. 2). Leaves of MM-Cf9 plants are poorly colonized by the B51 $\Delta A v r 9$ strain (Fig. 2A), when compared with the colonization of the MM-Cf0 plants (Fig. 2B). Furthermore, the mycelium appears swollen in leaves from MM-Cf9 plants, which is not observed in leaves from MM-Cf0 plants (Fig. 2A, see arrows). However, inhibition of fungal growth does not reach the level exhibited by MM-Cf9 plants when inoculated with the natural AVR9producing race 5 , where hyphae are eventually contained within the area of cells showing HR (Fig. 2C). Similar results were obtained for the A $43 \Delta A v r 9$ and race 4 strains.

To extend the microscopical observations, we determined the accumulation of two in planta-secreted proteins of $C$. fulvum, ECP1 (Joosten and De Wit 1988) and ECP2 (Wubben et al. 1994), by immunodetection. These proteins can be used as quantitative markers of the fungal biomass in planta (Laugé et al. 1997). Proteins present in apoplastic fluids (AFs) were subjected to polyacrylamide gel electrophoresis (PAGE) and Western blots (immunoblots) were probed with antibodies raised against the two proteins. The results obtained with the ECP1 antibodies are shown in Figure 3. MM-Cf0 plants inoculated with either the wild-type strain or with the corresponding Avr9-disrupted strain show accumulation of ECP1 to similar levels (compare lanes 1 and 3, and 5 and 7). However, AFs from MM-Cf9 plants inoculated with the A43 $\triangle A v r 9$ or B51 $14 v v 9$ strains show much less accumulation of ECP1 when compared with MM-Cf0 plants inoculated with these strains (compare lanes 3 and 4, and 7 and 8). No accumulation of ECP1 was detected in AFs from MM-Cf9 plants inoculated with the natural AVR9-producing strains (lanes 2 and 6). Similar results were obtained upon immunodetection of ECP2 (results not shown). These results indicate that the weak resistance results in inhibition of fungal growth in the leaf mesophyll.

Macroscopic observations showed that, associated with less severe disease symptoms, both the $\mathrm{A} 43 \Delta A v r 9$ and B51 $\Delta A v r 9$ strains exhibit reduced conidiation on MM-Cf9 plants when compared with MM-Cf0 plants (Fig. 1C and D).

\section{The weak resistance response is associated with accumulation of high levels of PR proteins and extensive leaf chlorosis.}

We analyzed whether the observed levels of resistance are associated with different levels of pathogenesis-related (PR) protein accumulation. AFs obtained after inoculation of MM-Cf0 and MM-Cf9 plants, either with the strains race 4 and race 5 or with the $\mathrm{A} 43 \Delta A v r 9$ and $\mathrm{B} 51 \Delta A v r 9$ strains, were analyzed by sodium dodecyl sulfate (SDS)-PAGE. Samples were harvested every 2 days between 12 and 20 days post inoculation. Similar patterns were obtained for each time point and Figure 4 shows the protein profiles of the various AFs 12 days post inoculation. The highest levels of $\mathrm{PR}$ protein accumulation are observed in MM-Cf9 geno- 

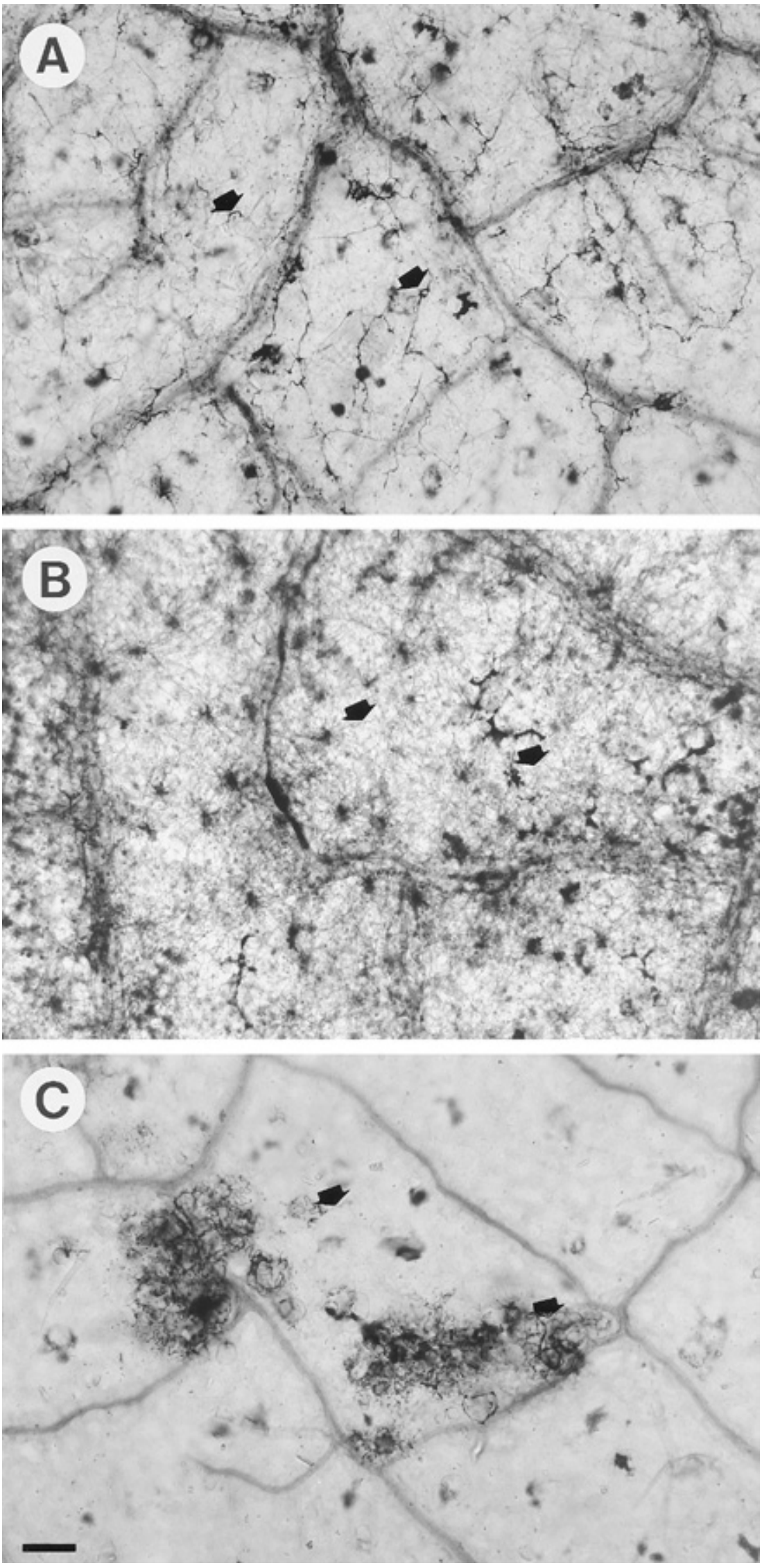
types inoculated with the A43 $4 A v r 9$ and B51 $\Delta A v r 9$ strains (lanes 5 and 9). In particular, P69 (Vera and Conejero 1988), $\beta$-1,3-glucanases (Joosten and De Wit 1989), and the 15kDa P14 protein family (Joosten et al. 1990) accumulate to high levels. There is also accumulation of PR proteins in both the fully compatible (lanes 2, 4, 6, and 8) and incompatible (lanes 3 and 7) interactions, but much less than in the interactions in which the plant displays weak resistance. The accumulation of the various families of PR proteins was confirmed by Western blot analysis (results not shown).

Inoculation of the $\mathrm{A} 43 \Delta A v r 9$ or $\mathrm{B} 51 \Delta A v r 9$ strains on MM-Cf9 plants led to early and extensive chlorosis, easily detectable from the upper side of the leaf, as illustrated with MM-Cf9 plants inoculated with the B51 $\Delta A v r 9$ strain in Figure $1 \mathrm{E}$.

\section{One natural strain of $C$. fulvum that overcomes the $C f$-9-mediated resistance can also overcome the weak resistance.}

We were interested to test whether natural strains of $C$. fulvum that overcome the $C f$-9-mediated resistance are unable to overcome the weak resistance present on the $C f-9$ introgression segment, or whether some strains would exist that are able to overcome both resistances. We tested the few known strains that lack the Avr9 gene from different geographical origins and inoculated them onto MM-Cf0 and MM-Cf9 plants. Based on symptom development and accumulation of ECP1 and ECP2 in planta, we found that the most recently isolated strain, strain 2679, caused disease symptoms on MMCf9 plants as severely as on MM-Cf0 plants (Figs. 1F, 5A). Consistently, the level of PR protein accumulation did not differ between MM-Cf9 plants and MM-Cf0 plants when inocu-

Fig. 2. Colonization of the leaf mesophyll, 3 weeks post inoculation of (A) MM-Cf9 plants with B51 $\Delta A v r 9$, (B) MM-Cf0 plants inoculated with race 5, (C) MM-Cf9 plants inoculated with race 5. Arrows point to fungal mycelium. A few hyphae are present in A; the mesophyll is fully colonized by mycelium in $\mathbf{B}$, and fungal growth is arrested in $\mathbf{C}$. Bar $=100 \mu \mathrm{m}$.

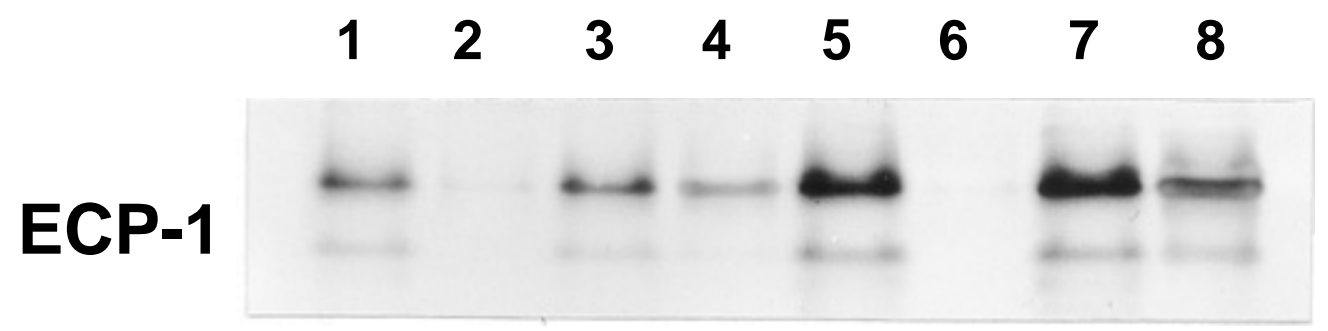

Fig. 3. Immunodetection of the fungal, in planta-secreted ECP1 protein with $5 \mu$ l of apoplastic fluids (AFs) obtained 20 days post inoc ulation from the following interactions: lane 1, MM-Cf0 plant inoculated with race 4; lane 2, MM-Cf9 plant inoculated with race 4; lane 3, MM-Cf0 plant inoculated with A43 $\Delta A v r 9$; lane 4, MM-Cf9 plant inoculated with A43 4 Avr9; lane 5, MM-Cf0 plant inoculated with race 5; lane 6, MM-Cf9 plant inoculated with race 5; lane 7, MM-Cf0 plant inoculated with B51 $\Delta A v r 9$; lane 8, MM-Cf9 plant inoculated with B51 $\Delta A v r 9$. Under native high-pH polyacrylamide gel electrophoresis conditions, ECP1 gives a double band most probably due to the presence of two differently processed forms of ECP1 in AF.

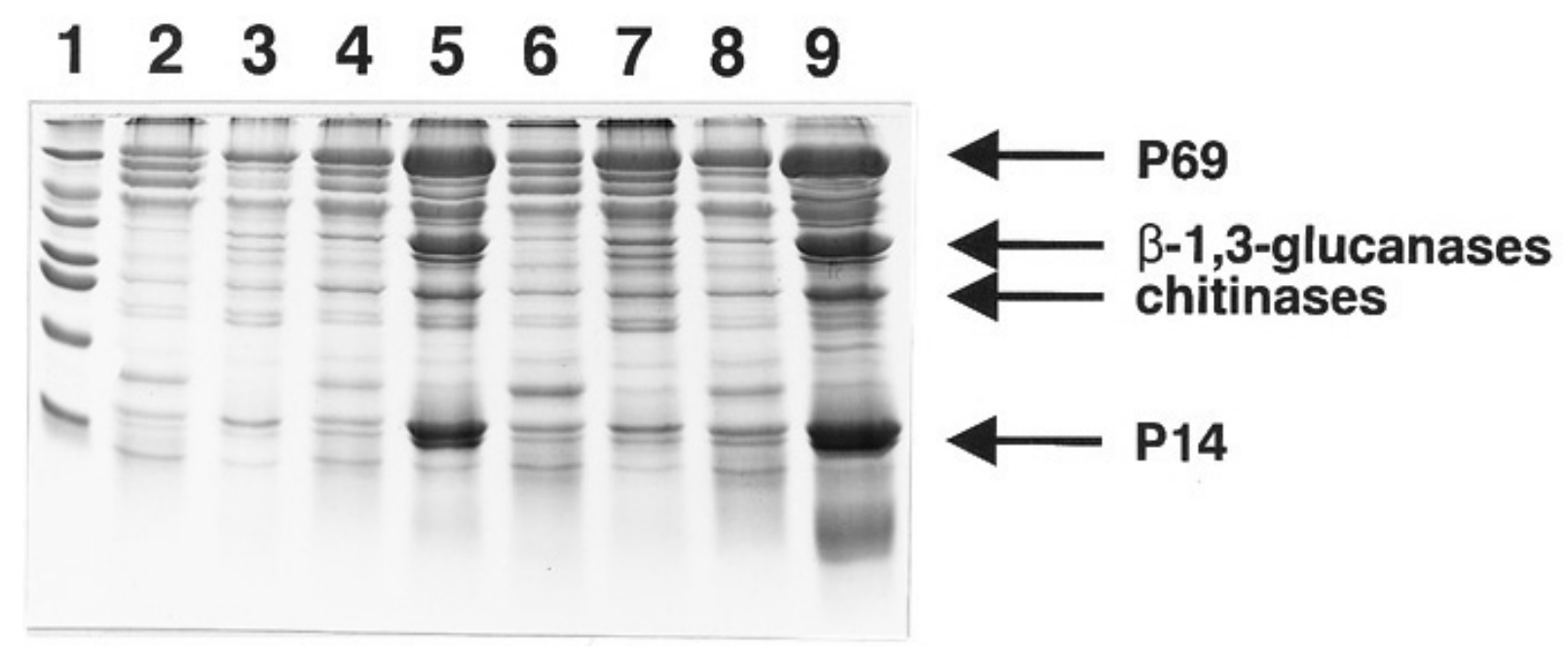

Fig. 4. Analysis by sodium dodecyl sulfate-polyacrylamide gel electrophoresis of $100 \mu \mathrm{l}$ of apoplastic fluid isolated from leaflets 12 days post inoculation. Lane 1, molecular weight marker; lane 2, MM-Cf0 plant inoculated with race 4; lane 3, MM-Cf9 plant inoculated with race 4; lane 4, MM-Cf0 plant inoculated with A43 $\Delta A v r 9$; lane 5, MM-Cf9 plant inoculated with A43 $\triangle A v r 9$; lane 6, MM-Cf0 plant inoculated with race 5; lane 7, MM-Cf9 plant inoculated with race 5; lane 8, MM-Cf0 plant inoculated with B51 $\Delta A v r 9$; lane 9, MM-Cf9 plant inoculated with B51 $A$ Avr9. Classes of the most abundant pathogenesis-related proteins that accumulate in the apoplast are marked by an arrow (P69, $\beta$-1,3-glucanases, chitinases, and P14). 
lated with strain 2679 (Fig. 5B). All other strains tested showed the same difference in disease symptoms on MM-Cf9 and on MM-Cf0 plants as was observed for the A $43 \Delta A v r 9$ and B51 $1 A v r 9$ mutants. This is illustrated for the strain NZb (Fig. $1 F)$. Similarly, these strains triggered a higher level of PR protein accumulation upon inoculation on MM-Cf9 plants when compared with inoculation on MM-Cf0 plants (data not shown). Thus, in addition to overcoming the $C f-9-$ mediated resistance, the strain 2679 is able to overcome the weak resistance.

\section{DISCUSSION}

Here we present evidence for the existence of a gene or genes conferring weak resistance to $C$. fulvum in tomato, in addition to the $C f-9$ resistance gene, on the $C f$-9-containing segment introgressed from $L$. pimpinellifolium PI126933. The weak resistance, which is independent of the production of AVR9 by the invading fungus and of the presence of a functional $C f-9$ gene, is associated with reduced colonization of the tomato leaf, reduction of conidia production, and strong accumulation of PR proteins in the apoplast of the infected leaves. A survey of Avr9 mutants occurring in nature identified one strain that overcomes the weak resistance.
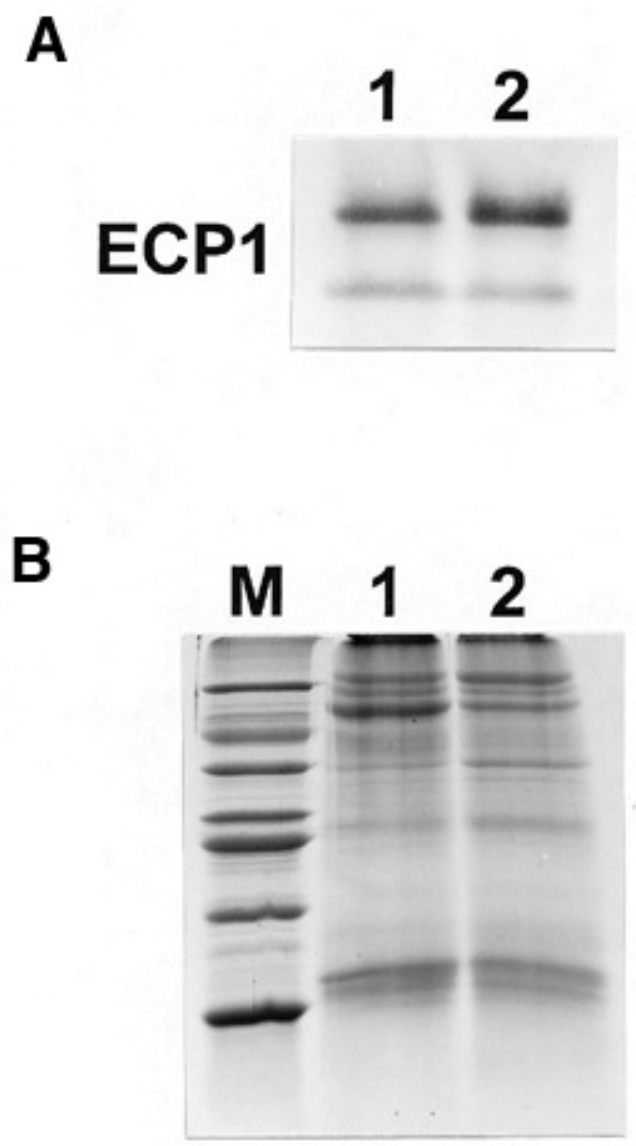

Fig. 5. A, Immunodetection of the fungal, in planta-secreted ECP1 protein with $5 \mu \mathrm{l}$ of apoplastic fluid (AF) obtained 20 days post inoculation of strain 2679 on the indicated genotypes. Lane 1, MM-Cf0; lane 2, MM-Cf9. B, Analysis by sodium dodecyl sulfate-polyacrylamide gel electrophoresis of $100 \mu \mathrm{l}$ of AF isolated from leaflets 12 days post inoculation of the strain 2679 on the indicated genotypes. Lane M, molecular weight marker; lane 1, MM-Cf0; lane 2, MM-Cf9.
The two Avr9-disrupted strains that were constructed by Marmeisse et al. (1993) were initially inoculated on 2-weekold MM-Cf9 seedlings and it was shown that the strains could overcome the $C f$-9-mediated resistance (Marmeisse et al. 1993). However, seedlings are not suitable to detect quantitative differences in virulence, as we have previously reported for mutant strains of C. fulvum lacking either Ecp1 or Ecp2 (Laugé et al. 1997). Decrease in virulence was apparent upon inoculation of 6-week-old plants. Similarly, studies with the EMS $C f-9$ mutants did not reveal weak resistance, as they were performed on cotyledons of seedlings (HammondKosack et al. 1994). However, the authors reported increased necrosis near vascular tissue, which they suggested is due to the action of an additional weak resistance gene.

When Avr9 mutants are inoculated on MM-Cf0 and MMCf9 plants, it is clear that the phenotype is determined by a plant trait and not by a fungal trait. In our inoculation tests we did not detect any difference in virulence between the race 4 and $\mathrm{A} 43 \Delta A v r 9$ strains, or between the race 5 and $\mathrm{B} 51 \Delta A v r 9$ strains on MM-Cf0, suggesting that $A v r 9$ has no or a minor function in virulence of $C$. fulvum. Alternatively, it might be that the Avr 9 function is complemented by other genes in the genetic backgrounds of races 4 and 5 .

It has been shown that several of the $C f$ genes show epistasis for the resistance phenotype (Hammond-Kosack and Jones 1994). Therefore, it is conceivable that when several independent resistance genes against a certain strain of $C$. fulvum are originally present in one plant genotype, the strongest one will behave epistatically and mask the action of the weaker one(s). In order to reveal the presence of the weak gene(s), it is necessary to abolish the activity of the strong gene, either by deleting the avirulence gene encoding the matching eliciting compound in the particular fungal strain, or by inactivating the strong resistance gene itself in the plant. In our study the use of Avr9-disrupted strains and of EMS $C f-9$ mutants allowed the discovery of the weak resistance gene(s). Thus, the outcome of the interaction between strains of $C$. fulvum and MM-Cf9 plants appears to be the result of the activity of several independent resistances, as illustrated in Table 1.

Table 1. Resistance levels of tomato genotypes challenged by various strains of Cladosporium fulvum

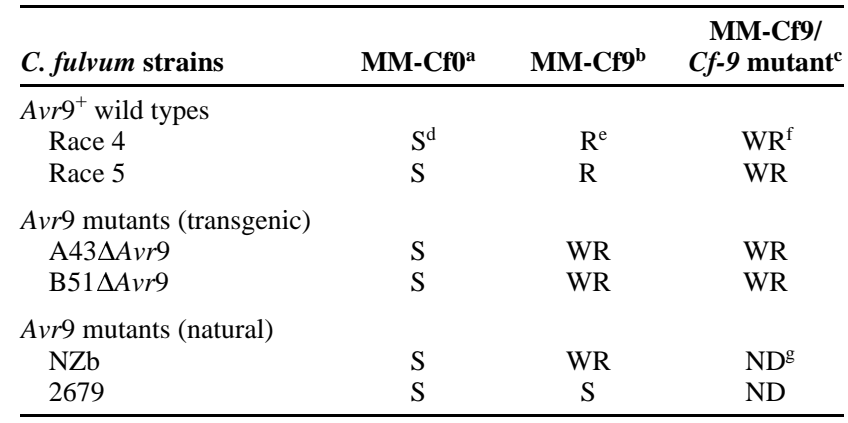

${ }^{\text {a }}$ Genotype lacking the $C f-9$ introgression segment.

${ }^{\mathrm{b}}$ Genotype containing the $C f-9$ introgression segment.

${ }^{c}$ Genotype containing the $C f-9$ introgression segment, without a functional $C f-9$ resistance gene.

${ }^{\mathrm{d}}$ Susceptible.

${ }^{\mathrm{e}}$ Highly resistant.

${ }^{\mathrm{f}}$ Weakly resistant.

g Not determined. 
An example of several linked resistance genes against the same pathogen at one locus is the two copies of the $C f$-2 gene (Dixon et al. 1996), and most of the resistance genes cloned so far have been found to be part of clusters of homologues (Bent 1996). For resistance toward C. fulvum in tomato, our data do not suggest that there is an equivalent situation for the $C f-4$ and $C f-5$ gene clusters, as colonization of race 4 and race 5 is similar on MM-Cf0, and on MM-Cf4 and MM-Cf5, respectively. This indicates that homologues different from the functional $C f-4$ and $C f-5$ genes do not govern any resistance to these races, or, alternatively, that race 4 and race 5 have already overcome these additional resistance genes.

There are some natural strains of $C$. fulvum that are able to overcome the functional $C f-9$ resistance gene (Lindhout et al. 1989). Although these strains have been known to exist for more than a decade, plant breeders envisage the $C f-9$ resistance gene as a strong gene. The presence of the additional weak resistance gene(s) probably explains why the strains of C. fulvum, reported to be able to overcome the $C f$-9-mediated resistance, are not causing a threat to tomato crops in practice, as these strains still encounter this weak resistance. Only the most recently isolated natural Avr9 mutant tested by us was able to overcome the weak resistance.

Different from $C f-9-$ mediated resistance, the weak resistance described here seems not to depend on HR enabling early containment of the fungus (Hammond-Kosack and Jones 1994). Possibly, delayed defense responses allow continuous escape of hyphae, causing a continuous stress to host cells over a large area and leading to unusually high levels of PR protein accumulation. It is most likely that the reported weak resistance is mediated by $C f-9$ homologue(s) present in the introgressed segment, though only transformation of MM-Cf0 tomato with individual homologues would give a definitive proof. Consequently, matching fungal elicitor(s) recognized due to the presence of the additional resistance gene(s) are predicted to exist. Leaf injection bioassay, as previously carried out to identify the AVR9 and AVR4 elicitors, did not trigger a visible response on MM-Cf9 plants. So other assays are required to achieve isolation and characterization of the matching fungal elicitors.

\section{MATERIALS AND METHODS}

\section{Strains and media, plants and inoculations.}

Culture conditions for the various strains of $C$. fulvum and tomato plants, as well as the inoculation procedure were according to De Wit (1977). The development of symptoms was followed in time and photographed 2 to 3 weeks post inoculation. All inoculations were conducted three times with two plant individuals per fungal strain/plant genotype combination, and we presented pictures of a representative experiment.

\section{Genotypes of plants and fungal strains.}

The set of tomato plants tested consisted of the following: the cv. Moneymaker (MM-Cf0), which does not contain any known genes for resistance against $C$. fulvum, and three nearisogenic lines of this cultivar; MM-Cf9, containing an introgression segment of L. pimpinellifolium PI126933 carrying the $C f-9$ resistance gene; MM-Cf4, containing an introgression segment of L. hirsutum PI370085 carrying the $C f-4$ resistance gene; and MM-Cf5, containing an introgression segment of $L$. esculentum var. cerasiforme PI187002 carrying the $C f-5$ gene (Stevens and Rick 1988). These three genotypes are known to be fully resistant via the introgressed resistance genes, $C f-9$, $C f-4$, or $C f-5$, which are directed toward fungal strains that contain the corresponding avirulence genes Avr9, Avr4, and Avr5, respectively. MM-Cf9/Cf-9 EMS mutants, M140 and M466 (Hammond-Kosack et al. 1994), were obtained from K. Hammond-Kosack (John Innes Center, Norwich, U.K.). The relevant genotypes of the fungal strains used in this study are the following: race $4\left(A v r 4\right.$ mutant, $\left.A v r 5^{+}, A v r 9^{+}\right)$; race 5 $\left(A v r 4^{+}\right.$, Avr5 mutant, Avr9 $9^{+}$); A43 4 Avr9 (Avr4 mutant, Avr5 $5^{+}$, Avr9 mutant); B51 $\Delta A v r 9$ (Avr4 $4^{+}, A v r 5$ mutant, Avr9 mutant) (Marmeisse et al. 1993). Natural Avr mutants NZb and 2679 were obtained from the collections of the Manaaki Whenua Landcare Research, Auckland, New Zealand and the Research Institute for Plant Protection, Wageningen, The Netherlands, respectively. Other natural $A v r 9$ mutants tested were from the collection of our laboratory.

\section{Light microscopy.}

Leaf disks were obtained from leaf material 3 weeks post inoculation. Staining of the intercellular fungal hyphae was as described by Laugé et al. (1997).

\section{Preparation and analysis of AFs.}

Six leaflets were randomly sampled from inoculated plants for preparation of AFs according to the method described by De Wit and Spikman (1982). Analysis of total soluble proteins was performed by $15 \%$ (wt/vol) SDS-PAGE of $100 \mu \mathrm{l}$ of freeze-dried AF. For immunodetection of individual PR proteins and the fungal ECP2 protein, the proteins present in $5 \mu \mathrm{l}$ of AFs were first separated with 15\% SDS-PAGE and subsequently transferred to Immobilon-P membrane (Millipore, Etten-Leur, The Netherlands). Antibodies raised against $\beta-1,3-$ glucanase, chitinase, and the three basic $15-\mathrm{kDa}$ PR proteins have been described previously (Joosten and De Wit 1989; Joosten et al. 1990: Wubben et al. 1994). For immunodetection of ECP1, the proteins present in $5 \mu \mathrm{l}$ of AF were separated by native high-pH PAGE $(\mathrm{pH} 8.8)$, before transfer to Immobilon-P. The antibodies against ECP1 have been described by Joosten and De Wit (1988).

\section{ACKNOWLEDGMENTS}

We thank K. Hammond-Kosack and J. Jones (John Innes Center, Norwich, U.K.) for providing the MM-Cf9/Cf-9 EMS mutants, M. Fletcher (Manaaki Whenua Landcare Research, Auckland, New Zealand) and E. Winterswijk (Research Institute for Plant Protection, Wageningen, The Netherlands) for providing natural Avr 9 mutants of $C$. fulvum, and M. Kooman-Gersmann for critically reading the manuscript. This work was supported by the European Community-Human Capital and Mobility program ERBCHRXCT930244 (R. Laugé and P. J. G. M. De Wit), the Nederlandse Organisatie voor Wetenschappelijk Onderzoek/Priority Program Crop protection 805.45.012 (M. H. A. J. Joosten), and by a research grant of the Wageningen Agricultural University (A. P. Dmitriev).

\section{LITERATURE CITED}

Bent, A. F. 1996. Plant disease resistance genes: Function meets structure. Plant Cell 8:1757-1771.

Day, P. R. 1956. Races names of Cladosporium fulvum. Rep. Tomato Genet. Coop. 6:13-14. 
Day, P. R. 1957. Mutation to virulence in Cladosporium fulvum. Nature 179:1141-1142.

De Wit, P. J. G. M. 1977. A light and scanning-electron microscopic study of infection of tomato plants by virulent and avirulent races of Cladosporium fulvum. Neth. J. Plant Pathol. 83:109-122.

De Wit, P. J. G. M., and Spikman, G. 1982. Evidence for the occurrence of race- and cultivar-specific elicitors of necrosis in intercellular fluids of compatible interactions of Cladosporium fulvum and tomato. Physiol. Plant Pathol. 21:1-11.

Dixon, M. S., Jones, D. A., Keddie, J. S., Thomas, C. M., Harrison, K., and Jones, J. D. G. 1996. The tomato $C f$-2 disease resistance locus comprises two functional genes encoding leucine-rich repeat proteins. Cell 84:451-459.

Hammond-Kosack, K. E., Jones, D. A., and Jones, J. D. G. 1994. Identification of two genes required in tomato for full $C f$-9-dependent resistance to Cladosporium fulvum. Plant Cell 6:361-374.

Hammond-Kosack, K. E., and Jones, J. D. G. 1994. Incomplete dominance of tomato $C f$ genes for resistance to Cladosporium fulvum. Mol. Plant-Microbe Interact. 7:58-70.

Hammond-Kosack, K. E., and Jones, J. D. G. 1997. Plant disease resistance genes. Annu. Rev. Plant Physiol. Plant Mol. Biol. 48:575-607.

Jones, D. A., Brading, P., Dixon, M., Hammond-Kosack, K., Harrison, K., Hatzixanthis, K., Parniske, M., Piedras, P., Torres, M., Tang, S., Thomas, C., and Jones, J. D. G. 1996. Molecular, genetic and physiological analysis of Cladosporium resistance gene function in tomato. Pages 57-63 in: Biology of Plant-Microbe Interactions. G. Stacey, B. Mullin, and P. M. Gresshoff, eds. International Society for Molecular Plant-Microbe Interactions, St. Paul, MN.

Jones, D. A., Dickinson, M. J., Balint-Kurti, P. J., Dixon, M. S., and Jones, J. D. G. 1993. Two complex resistance loci revealed in tomato by classical and RFLP mapping of the $C f-2, C f-4, C f-5$, and $C f-9$ genes for resistance to Cladosporium fulvum. Mol. Plant-Microbe Interact. 6:348-357.

Jones, D. A., Thomas, C. M., Hammond-Kosack, K. E., Balint-Kurti, P. J., and Jones, J. D. G. 1994. Isolation of the tomato $C f-9$ gene for resistance to Cladosporium fulvum by transposon tagging. Science 266:789-793.

Joosten, M. H. A. J., Bergmans, C. J. B., Meulenhoff, E. J. S., Cornelissen, B. J. C., and De Wit, P. J. G. M. 1990. Purification and serological characterization of three basic 15-kilodalton pathogenesis-related proteins from tomato. Plant Physiol. 94:585-591.

Joosten, M. H. A. J., Cozijnsen, A. J., and De Wit, P. J. G. M. 1994. Host resistance to a fungal tomato pathogen lost by a single base-pair change in an avirulence gene. Nature 367:384-387.

Joosten, M. H. A. J., and De Wit, P. J. G. M. 1988. Isolation, purification and preliminary characterization of a protein specific for compatible Cladosporium fulvum (syn. Fulvia fulva)-tomato interactions. Physiol. Mol. Plant Pathol. 33:241-253.

Joosten, M. H. A. J., and De Wit, P. J. G. M. 1989. Identification of sev- eral pathogenesis-related proteins in tomato leaves inoculated with Cladosporium fulvum (syn. Fulvia fulva) as 1,3-ß-glucanases and chitinases. Plant Physiol. 89:945-951.

Kanwar, J. S., Kerr, E. A., and Harney, P. M. 1980. Linkage of $C f-12$ to $C f-24$ genes for resistance to tomato leaf mold, Cladosporium fulvum Cke. Rep. Tomato Genet. Coop. 30:22-23.

Kerr, E. A., and Bailey, D. L. 1964. Resistance to Cladosporium fulvum Cke obtained from wild species of tomato. Can. J. Bot. 42:1541-1554.

Langford, A. N. 1937. The parasitism of Cladosporium fulvum Cooke and the genetics of resistance to it. Can. J. Res. C 15:108-128.

Laugé, R., Joosten, M. H. A. J., Van den Ackerveken, G. F. J. M., Van den Broek, H. W. J., and De Wit, P. J. G. M. 1997. The in plantaproduced extracellular proteins ECP1 and ECP2 of Cladosporium fulvum are virulence factors. Mol. Plant-Microbe Interact. 10:725-734.

Lindhout, P., Korta, W., Cislik, M., Vos, I., and Gerlagh, T. 1989. Further identification of races of Cladosporium fulvum (Fulvia fulva) on tomato originating from the Netherlands, France and Poland. Neth. J. Plant Pathol. 95:143-148.

Marmeisse, R., Van den Ackerveken, G. F. J. M., Goosen, T., De Wit, P. J. G. M., and Van den Broek, H. W. J. 1993. Disruption of the avirulence gene avr 9 in two races of the tomato pathogen Cladosporium fulvum causes virulence on tomato genotypes with the complementary resistance gene $C f-9$. Mol. Plant-Microbe Interact. 6:412-417.

Scholtens-Toma, I. M. J., and De Wit, P. J. G. M. 1988. Purification and primary structure of a necrosis-inducing peptide from the apoplastic fluids of tomato infected with Cladosporium fulvum (syn. Fulvia fulva). Physiol. Mol. Plant Pathol. 33:59-67.

Stamova, L., and Yordanov, M. 1977. Cladosporium fulvum resistance derived from Solanum pennellii and L. hirsutum. Rep. Tomato Genet. Coop. 27:25

Stamova, L., and Yordanov, M. 1978a. A new gene for resistance to Cladosporium fulvum derived from $L$. chilense. Rep. Tomato Genet. Coop. 28:18-19.

Stamova, L., and Yordanov, M. 1978b. Genetic study of the genes for resistance to Cladosporium fulvum derived from $L$. cheesmanii. Rep. Tomato Genet. Coop. 28:19.

Stevens, M. A., and Rick, C. M. 1988. Genetics and breeding. Pages $35-$ 109 in: The Tomato Crop. E. H. Roberts, ed. Chapman and Hall, London.

Van den Ackerveken, G. F. J. M., Van Kan, J. A. L., and De Wit, P. J. G. M. 1992. Molecular analysis of the avirulence gene avr9 of Cladosporium fulvum fully supports the gene-for-gene hypothesis. Plant J. 2:359-366.

Vera, P., and Conejero, V. 1988. Pathogenesis-related proteins of tomato. P-69 as an alkaline endoproteinase. Plant Physiol. 87:58-63.

Wubben, J. P., Joosten, M. H. A. J., and De Wit, P. J. G. M. 1994. Expression and localization of two in planta induced extracellular proteins of the fungal tomato pathogen Cladosporium fulvum. Mol. Plant-Microbe Interact. 7:516-524. 